\title{
Landscape perception of local population: the relationship between ecological characteristics, local society and visitor preferences
}

\author{
P. Díaz ${ }^{1}$, D. Ruiz-Labourdette ${ }^{1}$, A. R. Darias $^{2}$, A. Santana ${ }^{2}$, \\ M. F. Schmitz ${ }^{1} \&$ F. D. Pineda ${ }^{1}$ \\ ${ }^{I}$ Complutense University of Madrid, Spain \\ ${ }^{2}$ La Laguna University, Spain
}

\begin{abstract}
Previous research has described and mapped the 'visitor-landscape' correspondence in terms of 'demand' and 'offer'. The relationship between the landscape and the socio-economic structure of the local population has also been studied, enabling us to create scenarios of change. Other relationships are being studied in order to provide an understanding both of the local population and of the tourism industry within the context of the 'landscape resource', in an attempt to produce results, both for this industry and for the sensible and sustainable management of the above mentioned resource.

In the present paper we focus on the island of Fuerteventura (Canary Isles, Spain) and attempt to describe an assessment of the landscape by local populations - 'local population-landscape' correspondence - and compare it with the perception of visitors - 'visitors-landscape' correspondence. The results show a clear parallelism between the appreciation of the island's landscape by visitors and locals. The former consider the variable 'sun' to be essential in their appreciation of the landscape, this factor constituting the reason for their visit, whereas the latter value the landscape more highly than the visitors, taking it as something associated with the traditional rural world and as a reason to feel proud. This could be explained by means of a relaxed visit to the island from an anthropologist's perspective. A comparison between the 'assessment of the landscape by the local population' and 'landscape demand by visitors' can also be mapped, and could be better explained within the context of the research to which the present paper belongs.
\end{abstract}


Keywords: identity of human perception, landscape values, landscape management, landscape perception and preferences, tourist areas.

\section{Introduction}

The loss of identity in some sectors of local society in tourist areas has been noted by several authors as a remarkable feature. Although society appears to appreciate its natural and traditional cultural landscapes, a loss of identity resulting from tourism might also imply a lower degree of valuation of the landscape. This identity loss might therefore lead to the practical disappearance of a society's character and personality. The phenomenon can be disastrous both for tourism and for local people themselves. Visitors, meanwhile, consider landscape and climate to be the main attractions of a destination. Mountains, coast and the traditional rural landscape all appear to be reasons for extended visits. Likewise, historical and monumental heritage, whether urban or not, seems to be subject to shorter visits. All of these sites should be very comfortable in the climatic sense, and the landscape must not show too many signs of abandonment.

Each cultural landscape has features that make it unique, especially for local inhabitants. After many generations, local people provide a clear character and identity to a place or region (Antrop [1]). Landscape identity therefore concerns those landscape attributes characterising an area and distinguishing it from others (Palmer and Roos-Klein Lankhorst [2], Green [3]). The cultural identity of local populations appears to be closely related to the ways in which people interact with their landscapes and the local values thereof create a distinctive identity that comprises the relationship between people and the landscape (Stephenson [4]). Several authors have argued that landscape perception and preferences are dependent on the cultural background and personal attributes of the observer, but there is an intense interaction between the identity of a landscape and the cultural or personal identity of the people living in an area (Bernáldez [5, 6], Tveit et al. [7]). Thus, perception and assessment of landscapes differ widely among different societies and cultures, and the landscape preferences of landscape planners, decision-makers or visitors usually differ from those of the local people (Ayad [8], Dramstad et al. [9], De Aranzabal et al. [10]). This is especially evident in tourist areas in which a remarkable characteristic involves a loss of identity of some sectors of local society. Although this society appears to appreciate its traditional natural and cultural landscapes, identity loss resulting from tourism might also imply a lower level of appreciation of the landscape. Thus, loss of identity can cause a society's character and personality to practically disappear. This phenomenon can pose a serious problem both for tourism and for local people.

Landscape is considered as a common value of society as a whole, and is used and valued by different types of people, which makes it a multifunctional concept (Antrop [11]). The visual landscape is one of the main domains where the work of planners and managers interacts with public perceptions and expectations, and it seems necessary to establish how different types of people 
react according to their profile, background and human experience with regard to determining landscape quality levels and to considering public participation in landscape management (Bell [12], Daniel [13]). The consequences of management on the visual quality of a landscape and on the perception thereof by those who live, work, and recreate in a specific area must be taken into account as a criterion of environmental planning and management (Van den Berg and Kool [14]).

Our team habitually works within this context. Previous research has described and mapped the 'visitor-landscape' correspondence in terms of 'demand' and 'offer' (Schmitz et al. [15], De Aranzabal et al. [10]) and the relationship between landscape and the socio-economic structure of the local population has also been studied, enabling simulation of change scenarios (Schmitz et al. [16], De Aranzabal et al. [17]). Other relationships are being researched, these focusing tourism within the context of the 'landscape resource' and of the local population. The results are useful to tourism and for landscape management and sustainability. Our objectives involve several interrelated questions: to what extent do the landscape preferences of the local population at a tourist destination tally with or differ from, those of the visitors? Do the landscape preferences of the local population show signs of identity loss? To what degree do the characteristics of the landscape in which local inhabitants work and live coincide with the ones they say they prefer when interviewed? Is there any relationship between what visitors do during their stay at the destination and what they say they appreciate about the landscape when interviewed? What relationship is there between the parameters of 'tourism excellence' found in tourist brochures and the real image of the landscape? Some of these questions are addressed in publications by WIT press. In the present paper we focus on the island of Fuerteventura (Canary Isles, Spain) and attempt to establish an assessment of landscape by local populations -'local populationlandscape' correspondence - and compare it with perception of visitors 'visitors-landscape' correspondence. Our approach enables us to quantify and compare assessments of the scenic quality of Fuerteventura's landscape characteristics by local people and by visitors who use this landscape for recreation and leisure. In the context of these questions, our approach provides a useful tool for the development and application of suitable techniques for different landscape management strategies and conservation in which to fully consider the views of different stakeholders involved.

\section{Study area}

Fuerteventura is one of the Canary Isles' largest islands $\left(1731 \mathrm{~km}^{2}\right)$. It is a desert island with $110 \mathrm{~mm}$ of rainfall, hardly reaching $200 \mathrm{~mm}$ at the highest elevations, with unique and attractive volcanic landscapes and notably broad visual basins. Most of the land is ochre-coloured, with outcrops of black basaltic rocks in many places inland and on some coastal cliffs. There are also spectacular beaches. The main rural traditional activities are extensive agriculture, extensive goatherding and coastal artisanal fishing. Agriculture has 
been concentrated in some valley bottoms and some flat areas and slope zones with characteristic terraces (gavias), where some varieties of early cereals have been successfully grown. In the last decade, rural abandonment has run parallel to the development of mass 'sun and sand' tourism (Ruiz-Labourdette et al. [18]).

\section{Methodological approach}

\subsection{Surveys of local people and visitors}

We conducted surveys based on questionnaires among local people and visitors to the area. We used a structured and standardized questionnaire which had previously been tested in other areas and adapted to the characteristics of the study area $[10,15]$. The questionnaires were based on the characterization of landscape preferences (Table 1). In designing the questionnaires we considered a limited number of questions that could be answered quickly and easily. Respondents had to assess their responses on an ordinal scale from 0 to 5, according to their preferences. The interviews were conducted by skilled interviewers who read the questions to the respondents in order to obtain reliable answers (Van der Zee [19], Hughey et al. [20]). The interviewees were selected randomly from the visitors, when they were returning from their trip and from the local people, by means of stratified random sampling that considered the island's 24 population settlements. Data were collected over one year. In this sampling 200 contacts were made among local people and 200 among groups of visitors. In order to avoid any possible redundancy in answers, on interviewing a group of people, we followed a criterion consisting of not interviewing more than two people from the same group.

Table 1: Questions from the survey of the local population and visitors regarding the environmental aspects of Fuerteventura.

\begin{tabular}{|c|c|}
\hline - Autumn and winter temperatures & - Natural landscape \\
\hline - Avifauna, birdwatching & - Open valleys with few houses \\
\hline - Beaches & $\begin{array}{c}\text { - Rural landscape, agriculture, gavias } \\
\text { (small fields with stone or earth walls) }\end{array}$ \\
\hline - Climatic comfort & - Shrublands, cactus fields \\
\hline - Closed agricultural valleys & - Strong winds \\
\hline - Coastal cliffs & - Sun, intense sunshine \\
\hline - Coastal vegetation, brine basins & - Terrestrial fauna \\
\hline - Cool in summer & - Traditional architecture \\
\hline - Desert steppes & - Traditional fishing villages \\
\hline - Dunes & - Traditional villages \\
\hline - Large open valleys & - Valleys with palm trees \\
\hline - Lava fields (malpaís) & - Vegetation, flora \\
\hline - Marine fauna, cetaceans, & - Volcano landscape \\
\hline - Mountains with rocks & - Warmth in winter \\
\hline
\end{tabular}




\subsection{Design of raw data matrices}

We designed two data matrices with the same dimensions: 200 observations (number of questionnaires) x 28 variables (answers to the questions). The first matrix (landscape preferences matrix of local population) contained the data collected from the local population ( $a_{i j}=$ assessment of the landscape feature $i$ by the local people $j$ ) while the second one (landscape preferences matrix of visitors) contained the data collected from the visitors of the area $\left(b_{i j}=\right.$ assessment of the landscape feature $i$ by the visitor $j$ ).

\subsection{Similarities and differences}

We applied a discriminant canonical analysis (DA) to obtain a function that differentiates between the two datasets, visitors and locals, in accordance with the respective preferences of each set,

$$
\text { Group }=a+b_{1} * x_{1}+b_{2} x_{2}+b_{3} x_{3}+\ldots+b_{m}+x_{m}
$$

where $a$ is a constant and $b_{1}$ to $b_{m}$ are regression coefficients and the variables $x_{1}$ to $x_{m}$ represent de main discriminant landscape features preferences between local people and visitors.

\section{Results and discussion}

Figure 1 shows the mean values of visitors' and locals' preferences in relation to the perceived features of Fuerteventura's landscape. There is no apparent important difference between answers. Both groups of people answer similarly to the questions in the interviews, but an ANOVA of both sets shows a significant difference $(\mathrm{F}=8.72 ; \mathrm{p}<0.03)$. In relation to a low number of landscape features, the visitors show a greater preference compared with the locals, specifically in that they are attracted by the sun, a factor not highly valued by the locals (characteristic 26; Fig. 1). Sun, vegetation and flora (27) and wind (28) are the features least valued by the local population. Sunshine is constant on Fuerteventura throughout the year, and the local population does not consider it anything out of the ordinary. Cool summers (23) are really quite unusual on the island, but visitors value this factor somewhat more highly than locals. Locals do not value very highly the vegetation or the flora on an island where endemisms and rare plant communities can be found, which are more appreciated by visitors (although less that the remaining characteristics) than by locals. The latter consider these factors as something commonplace and therefore do not appreciate them much. The wind is very strong on Fuerteventura, an island subjected to the influence of the trade winds, against which the topography of the island can do little, something which occurs on other islands in the Canaries. The wind is slightly more appreciated by some visitors who practice sailing or kite board. Fuerteventura hardly reaches mid-mountain altitudes in the rocky massif in the SW. Although this is not very high compared with other islands, it is 


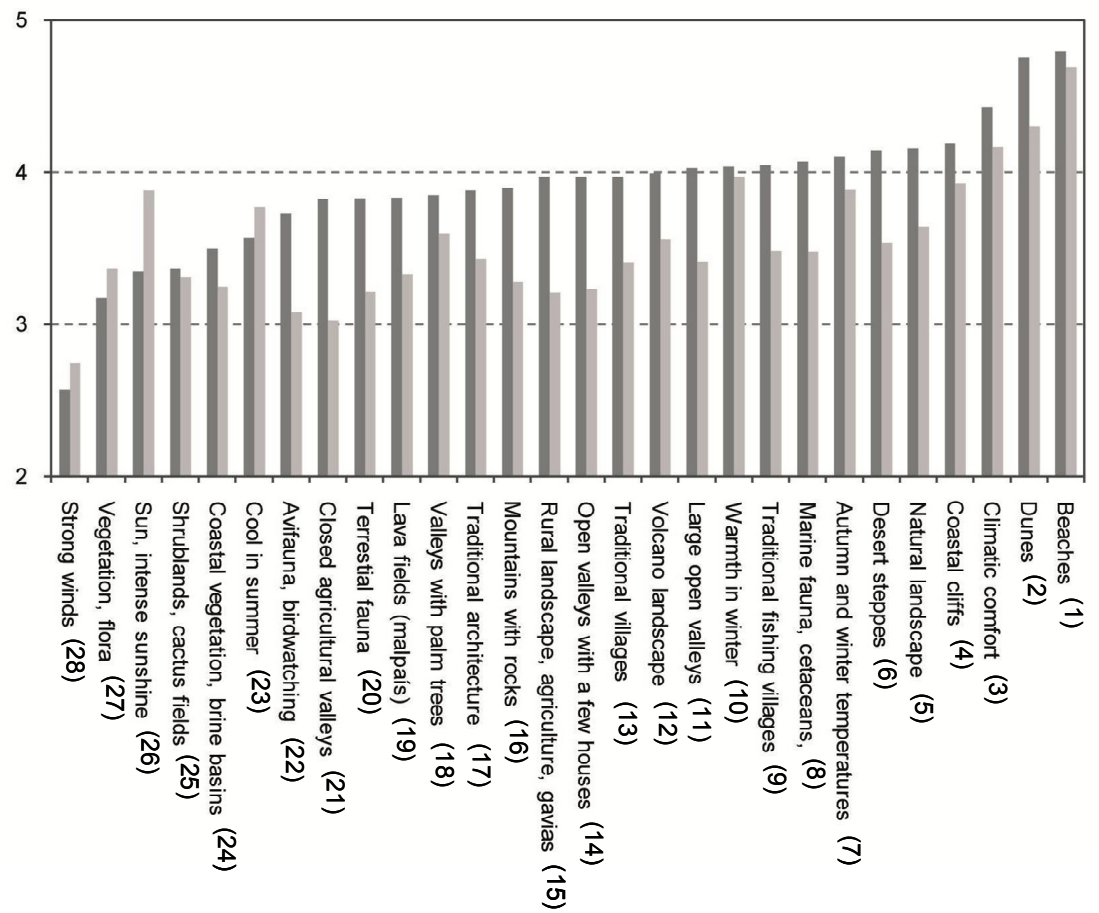

Figure 1: Representation of the mean values of preferences, in relation to Fuerteventura's landscape features, of a group of 200 visitors and the same number of locals. Appearing from right to left are the differential values assigned by the locals to these features (dark stripes; visitors are shown in light-coloured stripes).

relatively well appreciated by the local population (this characteristic takes $16^{\text {th }}$ place out of 28).

The differences between locals and visitors can also be seen in some other preferences. Beaches (1) and, above all, dunes (2) constitute the usual image of the tourist taking photos on the island, given the fact that they are quite spectacular. These are the characteristics most highly valued by the visitor but, as occurs with most of the island's landscape features, locals value them even more highly than visitors and feel proud of them (the island's brochures and tourism web pages offer them as attractions; Rodríguez et al. [21]). The 'natural' character of the landscape (5), in that it is conserved on the island, is another characteristic that is highly valued by the local population, and it forms part of their traditions and songs, as with other highly valued characteristics (provided that there is no 'commercial' influence in their answers, with the idea in mind of The Canary Isles' tourism offer, which would call for a separate anthropological analysis). The components of the rural world are evidently more highly appreciated by locals than by visitors and it is interesting to note that the lava 


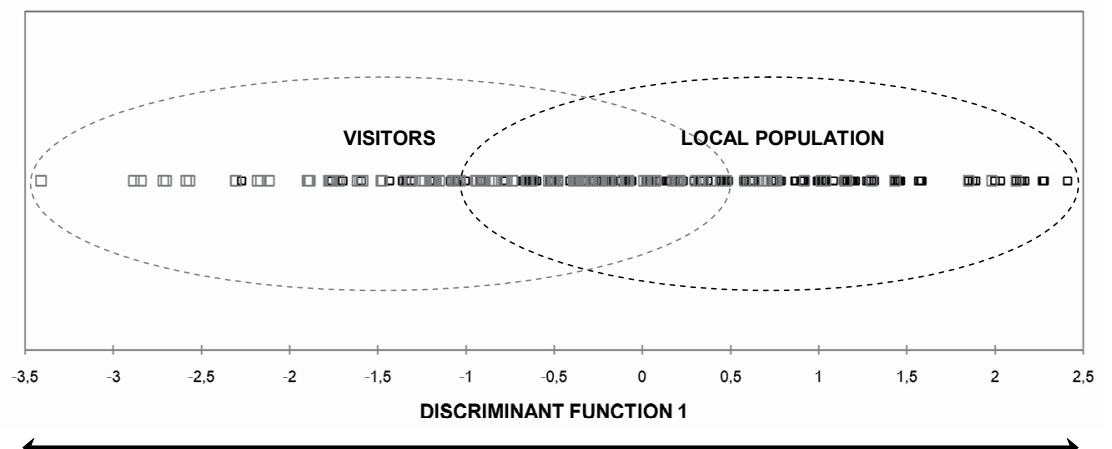

Sun, intense sunshine

Rural landscape, gavias Open valleys with a few houses Closed agrucultural valleys Terrestrial fauna Mountains with rocks

$F=-2.42+0.29 *$ Rural landscape $+0.28 *$ Open valleys with houses $+0.13 *$ Closed agricultural valleys $+0.12 *$ Mountains with rocks $+0.28 *$ terrestrial fauna $-0.42 *$ Sun, intense sunshine [percentage of incorrect classifications: visitors: $30 \%$; local population: $34 \%]$

Figure 2: $\quad$ Main discriminant canonical function obtained on differentiating between local population and visitor population based upon their respective appraisals of a set of 28 landscape features.

fields are also relatively more appreciated by the local population (19): in Spanish the word malpaís means bad territory, due to their being useless for agriculture.

Figure 2 shows the result of the DA. The preferences by the local population for the features of the rural landscape, mountains (uncommon on the island) and fauna are the ones that best differentiate between these people and visitors: the latter, on the contrary, are characterised by a very important discriminant variable: the sun.

According to this initial analysis, the results indicate that we apparently do not avail of entirely consistent data on the fears of the local population regarding identity loss due to tourism, at least on Fuerteventura, and in relation to appreciation of the landscape.

Other data remain to be analysed. Inhabitants on this island appear to identify with its natural and cultural landscape. Visitors also value this, with a similar variation tendency (Fig. 1), but to a lesser extent and with the reference of sun and sand tourism as their main interest in the island.

\section{References}

[1] Antrop, M., Why landscapes of the past are important for the future. Landscape and Urban Planning, 70, pp. 21-34, 2005.

[2] Palmer, J.F. \& Roos-Klein Lankhorst, J., Evaluating visible spatial diversity in the landscape. Landscape and Urban Planning, 43, pp. 65-78, 1998. 
[3] Green, R., Meaning and form in community perception of town character. Journal of Environmental Psychology, 19, pp. 311-329, 1999.

[4] Stephenson, J., The Cultural Values Model: An integrated approach to values in landscapes. Landscape and Urban Planning, 84, pp. 127-139, 2008.

[5] Bernáldez, F.G., Ecología y Paisaje. Blume: Madrid, 1981.

[6] Bernáldez, F.G., Invitación a la ecología humana. La adaptación afectiva al entorno. Tecnos: Madrid, 1985.

[7] Tveit, M., Ode, A. \& Fry, G., Key Concepts in a Framework for Analysing Visual Landscape Character. Landscape Research, 31(3), pp. 229-255, 2006.

[8] Ayad, Y.M., Remote sensing and GIS in modeling visual landscape change: a case study of the northwestern arid coast of Egypt. Landscape and Urban Planning, 73, pp. 307-325, 2005.

[9] Dramstad, W.E., Tveit, M.S., Fjellstad, W.J. \& Fry, G.L.A., Relationships between visual landscape preferences and map-based indicators of landscape structure. Landscape and Urban Planning, 78, pp. 465-474, 2006.

[10] De Aranzabal, I., Schmitz, M.F. \& Pineda, F.D., Integrating Landscape Analysis and Planning: A Multi-Scale Approach for Oriented Management of Tourist Recreation. Environmental Management, 44, pp. 938-951, 2009.

[11] Antrop, M., The concept of traditional landscapes as a base for landscape evaluation and planning. The example of Flanders Region. Landscape and Urban Planning, 38, pp. 105-117, 1997.

[12] Bell, S., Landscape pattern, perception and visualization in the visual management of forests. Landscape and Urban Planning, 54, pp. 201-211, 2007.

[13] Daniel, T.C., Whither scenic beauty? Visual landscape quality assessment in the $21^{\text {st }}$ century. Landscape and Urban Planning, 54, pp. 267-281, 2001.

[14] Van den Berg, A.E. \& Kool, S.L., New wilderness in the Netherlands: An investigation of visual preferences for nature development landscapes. Landscape and Urban Planning, 78, pp. 362-372, 2006.

[15] Schmitz, M.F., De Aranzabal, I. \& Pineda, Spatial analysis of visitor preferences in the outdoor recreational niche of Mediterranean cultural landscapes. Environmental Conservation, 34, pp. 300-312. F.D, 2007.

[16] Schmitz, M.F., de Aranzabal, I., Aguilera, P., Rescia, A. \& Pineda, F.D., Relationship between landscape typology and socioeconomic structure. Scenarios of change in Spanish cultural landscapes. Ecological Modelling, 168, pp. 343-356, 2003.

[17] De Aranzabal, I., Schmitz, M.F., Aguilera, P. \& Pineda, F.D., Modelling of landscape changes derived from the dynamics of socio-ecological systems. A case of study in a semiarid Mediterranean landscape. Ecological Indicators, 8, pp. 672-685, 2008.

[18] Ruiz-Labourdette, D., Díaz, P., Rodríguez, A.J., Santana, A., Schmitz, M.F. and Pineda, F.D., Scales and scenarios of change in the anthropologylandscape relationship: models of cultural tourism in Fuerteventura (Canary 
Isles). Island Sustainability, ed. S. Favro \& C.A. Brebbia, WIT Press: Southampton and Boston, pp. 51-64, 2010.

[19] Van der Zee, D., The complex relationship between landscape and recreation. Landscape Ecology, 4, pp. 225-236, 1990.

[20] Hughey, K.F.D., Cullen, R., Kerr, G.N. \& Cook, A.J., Application of the pressure-state-response framework to perception reporting of the state of New Zealand environment. Journal of Environmental Management, 70, pp. 85-93, 2004.

[21] Rodríguez, A., Díaz, P., Ruiz-Labourdette, D., Pineda, F.D., Dchmnitz, M.F. and Santana, A., Selection, design and dissemination of Fuerteventura's projected tourism image (Canary Isles). Island Sustainability, ed. S. Favro \& C.A. Brebbia, WIT Press: Southampton and Boston, pp. 13-24, 2010. 